\title{
High temperature tribological behaviour of PVD coated tool steel and aluminium under dry and lubricated conditions
}

\author{
Justine DECROZANT-TRIQUENAUX ${ }^{1,}$, Leonardo PELCASTRE ${ }^{1}$, Cédric COURBON ${ }^{2}$, Braham PRAKASH $^{1,3}$, \\ Jens HARDELL ${ }^{1}$ \\ ${ }^{1}$ Division of Machine Elements, Luleå University of Technology, SE-97187, Sweden \\ ${ }^{2}$ Université de Lyon, CNRS, Ecole Nationale d'Ingénieurs de Saint-Etienne, LTDS UMR5513, F-42023, France \\ ${ }^{3}$ Department of Mechanical Engineering, Tsinghua University, Beijing, 100084 China \\ Received: 11 February 2020 / Revised: 09 July 2020 / Accepted: 26 July 2020 \\ (C) The author(s) 2020.
}

\begin{abstract}
Aluminium alloys are commonly used as lightweight materials in the automotive industry. This non-ferrous family of metallic alloys offers a high versatility of properties and designs. To reduce weight and improve safety, high strength-to-weight ratio alloys (e.g. 6XXX and 7XXX), are increasingly implemented in vehicles. However, these alloys exhibit low formability and experience considerable springback during cold forming, and are therefore hot formed. During forming, severe adhesion (i.e. galling) of aluminium onto the die surface takes place. This phenomenon has a detrimental effect on the surface properties, geometrical tolerances of the formed parts and maintenance of the dies. The effect of surface engineering as well as lubricant chemistry on galling has not been sufficiently investigated. Diamond-like carbon (DLC) and CrN physical vapour deposition (PVD) coated steel have been studied to reduce aluminium transfer. However, the interaction between lubricants and PVD coatings during hot forming of aluminium alloys is not yet fully understood. The present study thus aims to characterise the high temperature tribological behaviour of selected PVD coatings and lubricants during sliding against aluminium alloy. The objectives are to first select promising lubricant-coating combinations and then to study their tribological response in a high-temperature reciprocating friction and wear tester. Dry and lubricated tests were carried out at $300^{\circ} \mathrm{C}$ using a commercial polymer lubricant. Tests using DLC, CrN, $\mathrm{CrTiN}$, and CrAlN coated tool steel were compared to uncoated tool steel reference tests. The initial and worn test specimen surfaces were analysed with a 3-dimensional (3D) optical profiler, scanning electron microscope (SEM) and energy dispersive X-ray spectroscope (EDS) as to understand the wear mechanisms. The results showed formation of tribolayers in the contact zone, reducing both friction and wear. The stability of these layers highly depends on both the coatings' roughness and chemical affinity towards aluminium. The DLC and CrN coatings combined with the polymer lubricant were the most effective in reducing aluminium transfer.
\end{abstract}

Keywords: high temperature tribology; aluminium; lubrication; physical vapour deposition (PVD) coatings; material transfer; adhesion

\section{Introduction}

Lightweight aluminium makes it a material of interest in many sectors and, particularly, the automotive industry. Typical alloys used as replacement for structural steel components are

* Corresponding author: Justine DECROZANT-TRIQUENAUX, E-mail: justine.decrozant-triquenaux@1tu.se 
the $6 X X X$ and 7XXX aluminium series, due to their superior strength-to-weight ratio. Thus, these alloys are promising candidates to enable the compliance of new vehicles with modern environmental energy consumption as well as passenger safety regulations.

Due to the limited formability of high strength aluminium alloys at low temperatures and the springback effect, these alloys are often formed at high-temperatures [1, 2]. Hot forming, and hot stamping in particular, are common manufacturing techniques for aluminium alloy components. These processes involve solubilisation of the aluminium work-piece, and subsequent forming in the dies at elevated temperatures (at around $0.6 \times \mathrm{Tm}$, where $\mathrm{Tm}$ is the melting temperature of aluminium [3]) and a final quenching step within the dies [2].

High-temperature forming of ductile and reactive materials such as aluminium alloys, leads to challenging tribological phenomena such as severe adhesion, often referred to as galling. This makes the manufacturing process problematic, especially due to the stringent time and cost requirements of current line production processes [4]. High adhesion and severe galling are critical wear mechanisms known to occur when forming aluminium at high temperatures [5-7]. These wear mechanisms affect the tool lifetime as well as the surface quality and the mechanical properties of the produced components [2, 3, 8, 9]. Thus, direct costs in forming (heating, tooling, and lubrication, etc.) and maintenance costs (refurbishing and stopping the lines, etc.) increase dramatically, hindering the attractiveness of using aluminium for mass production [1].

In order to address the tribological challenges and ensure viable production rates, different wear reduction strategies are employed in the industry. Such methods usually include the use of lubricants and surface engineering techniques [10].

High-temperature lubrication for the aluminiumsteel contact has, however, many limitations. Common lubricants such as oils decompose and degrade when in contact with surfaces hotter than $200{ }^{\circ} \mathrm{C}$, making them unsuitable lubricants for hot forming [11-13].
Solid lubricants such as graphite, $\mathrm{MoS}_{2}$ and boron compounds have been studied for aluminium forming [14-16]. Graphite exhibits good lubricity, high thermal stability and is suitable for the hot forming application [11, 13, 16]. Its use is however discouraged, due to health and environmental-related concerns, as well as cleanliness issues $[13,16] . \mathrm{MoS}_{2}$ is known to possess extremely low-friction in dry and vacuum conditions. Its use in air at high temperature however leads to rapid oxidation, adversely affecting its lubricity [11, 17]. Hexagonal boron nitride (hBN) based lubrication is promising due to its excellent lubricity and reduced health hazards [14, 18, 19]. However, the retention in the contact is essential for the efficiency of solid lubricants, and hBN compounds do not easily bond to contacting surfaces due to their low affinity to most surfaces, requiring the use of special formulations $[17,18]$.

Recently, there is a growing interest in polymer-based lubricants in view of the possibility of optimizing their properties and performance by combining different compounds [17, 20]. Wan et al. [20] reviewed inorganic polymer compounds as potential additives for improved lubrication at high-temperature. These have been found to effectively protect the surfaces in contact through the formation of tribolayers. The exact mechanisms are still not fully understood.

As highlighted by many authors in the literature in the past 20 years $[16,17,20]$, the hot forming lubricants currently in use are scarce, and there are only some isolated commercial products, developed for a particular set of working conditions. There is thus a need for systematic research to characterise and understand the tribological performance of these lubricants $[6,12,20]$, especially in the context of hot forming of aluminium alloys [10, 18].

Besides lubricants, new surface engineering approaches that include techniques for controlling the surface roughness of the dies as well as the use of surface coatings and treatments have emerged [21]. Several studies pertaining to the adhesion reducing abilities of different physical vapour 
deposition (PVD) coatings [22-25] as well as chemical vapour deposition (CVD) coatings [22, 24, 26] against aluminium have been conducted.

Jerina and Kalin [25] compared the tribological behaviour of a $\mathrm{H} 13$ tool steel and a CrN PVD coating during sliding against an AA6060 alloy. At high temperatures (e.g. above $400{ }^{\circ} \mathrm{C}$ ), the $\mathrm{CrN}$ coating has been found to reduce galling, leading to an improved friction behaviour. Pujante et al. [21] compared various tool steels to an AlCrN PVD coating when sliding against $99 \%$ purity aluminium balls. They found that even polishing did not prevent material transfer to occur, as the coating has a strong chemical affinity towards aluminium.

Pellizzari et al. [24] reported the behaviour of various as-deposited PVD coatings $(\mathrm{CrN}, \mathrm{TiCN}$, and TiAlN) on nitrided tool steel when sliding against hot AA6082. They found that, under dry conditions, both TiAlN and $\mathrm{CrN}$ coatings outperformed nitrided tool but none of the coatings could fully prevent galling under dry conditions.

Some selected diamond-like carbon (DLC) PVD coatings have also been reported to prevent aluminium transfer, due to their anti-sticking properties [22, 23]. $\mathrm{Ni}$ et al. [23] studied the influence of DLC coatings (hydrogenated vs. non-hydrogenated) and temperatures on adhesion against aluminium in dry conditions. They observed that above $120{ }^{\circ} \mathrm{C}$, both DLC coatings experience higher wear rates and more unstable friction than at room temperature.

Heinrichs et al. [22] have carried out in-situ scanning electron microscope (SEM) tribological experiments in order to characterize the initiation mechanisms of adhesion between aluminium and a DLC PVD coating. They proposed three classes of aluminium transfer: primary, secondary and damage activated. They classified the key parameters activating primary aluminium transfer as either of chemical (e.g. adhesive bonding) or mechanical (e.g. scratches and local defects) origin. Their study, however, was carried out at controlled low temperature, under vacuum and dry conditions.

It is evident that presently there is a lack of knowledge concerning effective ways to prevent the initiation of aluminium transfer at elevated temperatures. The effectiveness of high temperature lubricants, especially in combination with PVD coatings, for friction and wear control in tribosystems involving aluminium is also not fully understood. Furthermore, the published results about the role of PVD coating surface roughness on transfer of aluminium at elevated temperatures are scarce.

The aim of the present work is therefore to characterise the effect of PVD coating composition and topography on the aluminium transfer and friction behaviour under lubricated conditions at high temperature. The results have been compared to that of uncoated tool steel in dry and lubricated conditions in order to assess any potential synergistic effects between the coatings and lubricant.

\section{Experimental work}

\subsection{Materials and specimens}

A commercially available $\mathrm{Cr}-\mathrm{Mo}-\mathrm{V}$-alloyed hot work tool steel was used in uncoated and PVD coated conditions. Four different coatings (CrAlN, CrTiN, DLC ta-C, and $\mathrm{CrN}$ ) were applied to the hot work tool steel. The counter surface was an AA6016 aluminium alloy. The chemical composition of the materials, as provided by the supplier, and their measured microhardness values are shown in Table 1.

The microhardness and as-delivered measured thickness of the various PVD coatings was characterised from both the top (surface) and the PVD-substrate interface in the form of cross-section profiles. The respective results are

Table 1 Chemical composition (wt $\%$ ) and microhardness of the investigated materials ( $\mathrm{Fe}$ for the tool steel and $\mathrm{Al}$ for the aluminium make up the balance).

\begin{tabular}{lcccccccccc}
\hline Material & $\mathrm{C}$ & $\mathrm{Si}$ & $\mathrm{Mn}$ & $\mathrm{Cr}$ & $\mathrm{Mo}$ & $\mathrm{V}$ & $\mathrm{Mg}$ & $\mathrm{Zn}$ & $\mathrm{Cu}$ & $\mathrm{HV}_{0.1}$ \\
\hline Tool steel & 0.39 & 1.0 & 0.4 & 5.2 & 1.4 & 0.9 & - & - & - & $260 \pm 7$ \\
& & 1.0 & Max & $\mathrm{Max}$ & & & 0.25 & $\mathrm{Max}$ & $\mathrm{Max}$ & \\
Al6016 & - & -1.5 & 0.2 & 0.1 & & - & -0.6 & 0.2 & 0.2 & \\
& & -1.5 & & & & & & & & \\
\hline
\end{tabular}


given in Fig. 1. The top hardness measurements necessitated a higher load, due to the high system hardness (coating and substrate) making locating and measuring the indents difficult at low loads. The load of $200 \mathrm{~g}$ was thus chosen as to prevent cracking of the coatings, diminish the influence of roughness and get adequately sized indents. The system hardness is influenced by the thickness of the coatings, as the DLC ta-C and the CrN coatings exhibit the lower top hardness (around 1,100 $\mathrm{HV}_{0.2}$ ) as compared to the CrAlN and the CrTiN (around $\left.1,500 \quad \mathrm{HV}_{0.2}\right)$. The hardness profiles are also influenced by the coatings' thickness, as the DLC ta-C and $\mathrm{CrN}$ measurements were influenced by the free edge effect. The substrate was hardened through nitriding prior to the deposition of the coatings, in order to provide an improved mechanical support for the coatings. The nitriding has been found to be effective up to $100 \mu \mathrm{m}$ under the PVD coatings (Fig. 1). The hardness at the PVD-substrate interface varies from 500 to 1,300 $\mathrm{HV}_{0.01}$ and gradually decreases until the substrate

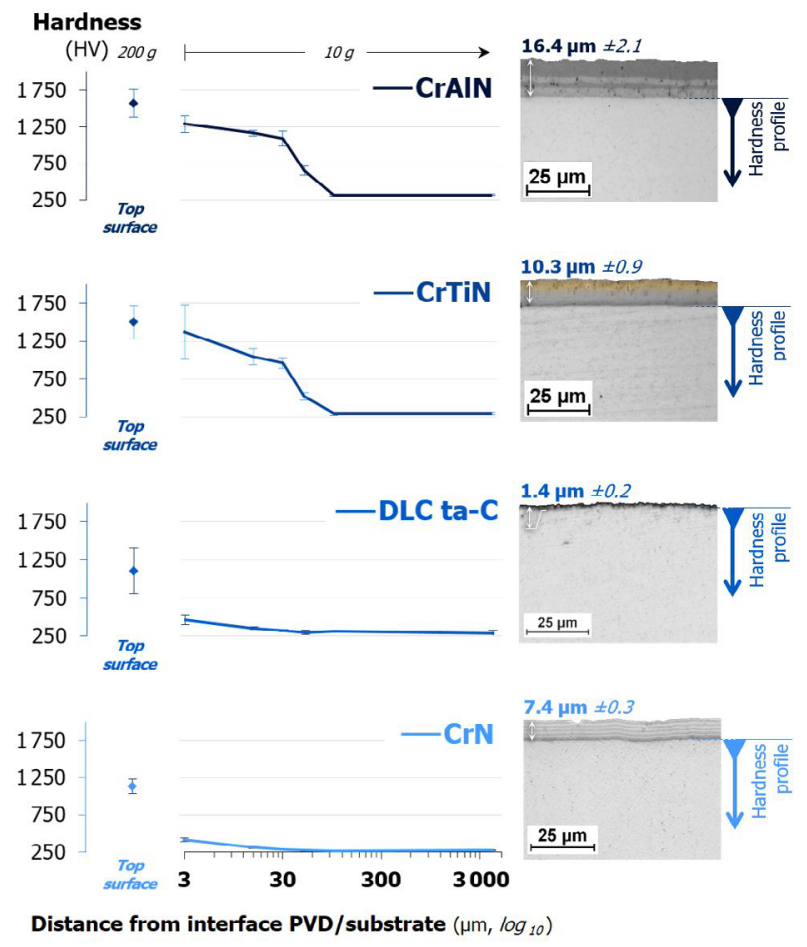

Fig. 1 Microhardness profiles measured on the PVD coatings and corresponding optical micrographs, highlighting the interface PVD-substrate from which the measurements were done (load $200 \mathrm{~g}$ for top, $10 \mathrm{~g}$ for profiles, load time $15 \mathrm{~s})$. hardness around $100 \mu \mathrm{m}$.

The test configuration was a flat pin-on-plate (area) contact. The tool steel specimens were in the form of $10 \mathrm{~mm}$ long $\varnothing 5 \mathrm{~mm}$ flat-end cylinders with $0.5 \mathrm{~mm}$ rounded edges and the aluminium alloy as $20 \mathrm{~mm} \times 20 \mathrm{~mm} \times 2 \mathrm{~mm}$ plates. The tribological tests were carried out under dry and lubricated conditions, using a commercially available warm forming lubricant (Lubrodal F $25 \mathrm{Al} ®$ ) consisting of an aqueous emulsion of polymer and siloxanes (further referred to as polymer).

To investigate the impact of PVD coating surface roughness on friction and wear, the $\mathrm{CrN}$ and CrTiN coated tool steel specimens were manually mirror polished. The polishing procedure involved fine polishing using 9, $3 \mu \mathrm{m}$ diamond-suspensions and a final $0.05 \mu \mathrm{m}$ colloidal silica suspension. The tests using post-polished specimens and as-received topographies are referred to as PP and $\mathrm{AR}$, respectively. An aluminium counter-surface was used in the as-received state in all the tests.

\subsection{Test equipment and procedure}

The test set-up was a standard Optimol SRV ${ }^{\circledR}$ high temperature reciprocating friction and wear tester, adapted to a flat-on-flat (pin on plate) contact configuration. The test involves an upper moving specimen (tool steel pin) and a lower stationary specimen (aluminium plate). An electromagnetic drive oscillates the upper specimen, which is loaded against the lower specimen using a spring deflection mechanism. The flat-on-flat contact configuration required accurate alignment of the test specimens before starting the heating cycle. This was ensured by means of a pressure sensitive film to assess the contact area and correct the tilt of the aluminium samples in relation to the tool steel pins before each test. The tool steel samples were the upper (moving) pin specimens, whereas the aluminium plates were fixed in the lower specimen holder. The tribotest parameters are given in Table 2. In the test set-up, active heating is applied only on the aluminium plate specimens. The test equipment, however, does not allow for controlled cooling rate. The physical limitation for cooling and tabilization of the temperature led to 
Table 2 Tribological test parameters.

\begin{tabular}{cccccc}
\hline $\begin{array}{c}\text { Load } \\
(\mathrm{N})\end{array}$ & $\begin{array}{c}\text { Contact } \\
\text { pressure } \\
(\mathrm{MPa})\end{array}$ & $\begin{array}{c}\text { Test } \\
\text { temperature } \\
\left({ }^{\circ} \mathrm{C}\right)\end{array}$ & $\begin{array}{c}\text { Sliding } \\
\text { frequency } \\
(\mathrm{Hz})\end{array}$ & $\begin{array}{c}\text { Sliding } \\
\text { speed } \\
(\mathrm{mm} / \mathrm{s})\end{array}$ & $\begin{array}{c}\text { Test } \\
\text { duration } \\
(\mathrm{s})\end{array}$ \\
\hline 10 & 0.6 & 300 & 12.5 & 100 & 30 \\
\hline
\end{tabular}

a fixed duration of $10 \mathrm{~min}$ until the test temperature was reached (equivalent to a cooling rate of around $24{ }^{\circ} \mathrm{C} / \mathrm{min}$ ).

The lubricant was manually applied (few drops) on the pin surface and left to dry in air at room temperature before mounting the pin in the tribometer. The aluminium plates underwent a solubilisation heat treatment (illustrated in Fig. 2) in the tribometer, before initiating the tests. The contact between the pin and the plate was not made until the beginning of the tribological test (i.e. only few seconds before sliding commenced).

Short contact times are typical during hot forming applications, where the total forming and quenching operations take approximately $10 \mathrm{~s}$ [27]. A test duration of $30 \mathrm{~s}$ was thus chosen in order to conduct the investigation at a consistent time scale but also to provide a sufficient time for running-in. Indeed, at the beginning of sliding, an unstable friction behaviour occurs as the system stabilises, generating an initial static-to-dynamic friction peak in all tests. The selected time also ensures enough sliding distance to induce repeatable wear and friction behaviour (30 s corresponding to $3 \mathrm{~m}$ at the chosen sliding speed).

The surfaces of both pin and plate samples were analysed before and after the tests using a 3-dimensional (3D) optical profiler for the topographical analyses; and a scanning electron

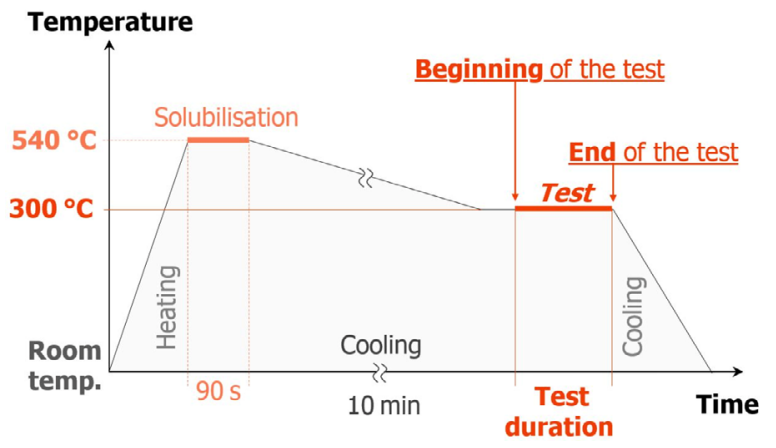

Fig. 2 Applied heat cycle (not to scale) to the aluminium sample previous to the tribotest. microscope (SEM) incorporating energy dispersive spectroscopy (EDS), in order to analyse the wear mechanisms. Nanoindentation of some specific features on the worn surfaces was performed in order to evaluate the mechanical properties of the tribolayers developed during sliding. These measurements were carried out at $0.5 \mathrm{mN}$ load, $0.0167 \mathrm{mN} / \mathrm{s}$ loading and unloading rate. The load was kept at its maximum for a dwell time of $30 \mathrm{~s}$ and thermal drift correction of $30 \mathrm{~s}$ was made after unloading. The averages were made over 100 indentations, for statistical value, due to the high scatter encountered during the measurements.

\section{Results and discussion}

\subsection{Unworn surfaces}

The arithmetic surface roughness $(S a)$ values of the different specimens are given in Fig. 3. The as-received specimens show Sa roughness levels between 400 and $100 \mathrm{~nm}$. The $\mathrm{Al}$ specimens exhibit a high roughness due to their specific as-received topography (shown in Fig. 4(e)). The manual post-polishing of the PVD coated samples greatly reduced the surface roughness.

In order to compare the changes in surface morphologies before and after the tribotests, SEM micrographs of the initial surfaces were taken. The as-received surface morphologies can be seen in Fig. 4. The PVD coated samples exhibit surface features typical from the PVD coating process, e.g. droplets. The CrAlN coated samples (Fig. 4(a)) exhibit few small droplets and craters. Titanium and chromium nitrides droplets were identified by

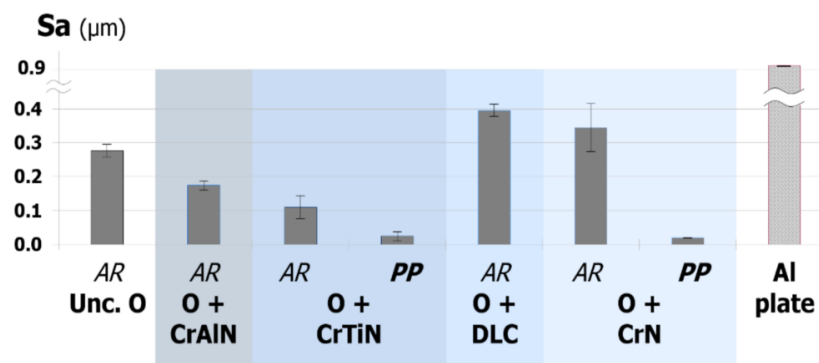

Fig. 3 Average arithmetic roughness on a $2 \mathrm{~mm} \times 2 \mathrm{~mm}$ surface of the pin specimens (ISO 25178, $\lambda_{\mathrm{c}} 0.25 \mu \mathrm{m}$ ) (three measurements for each configuration). 

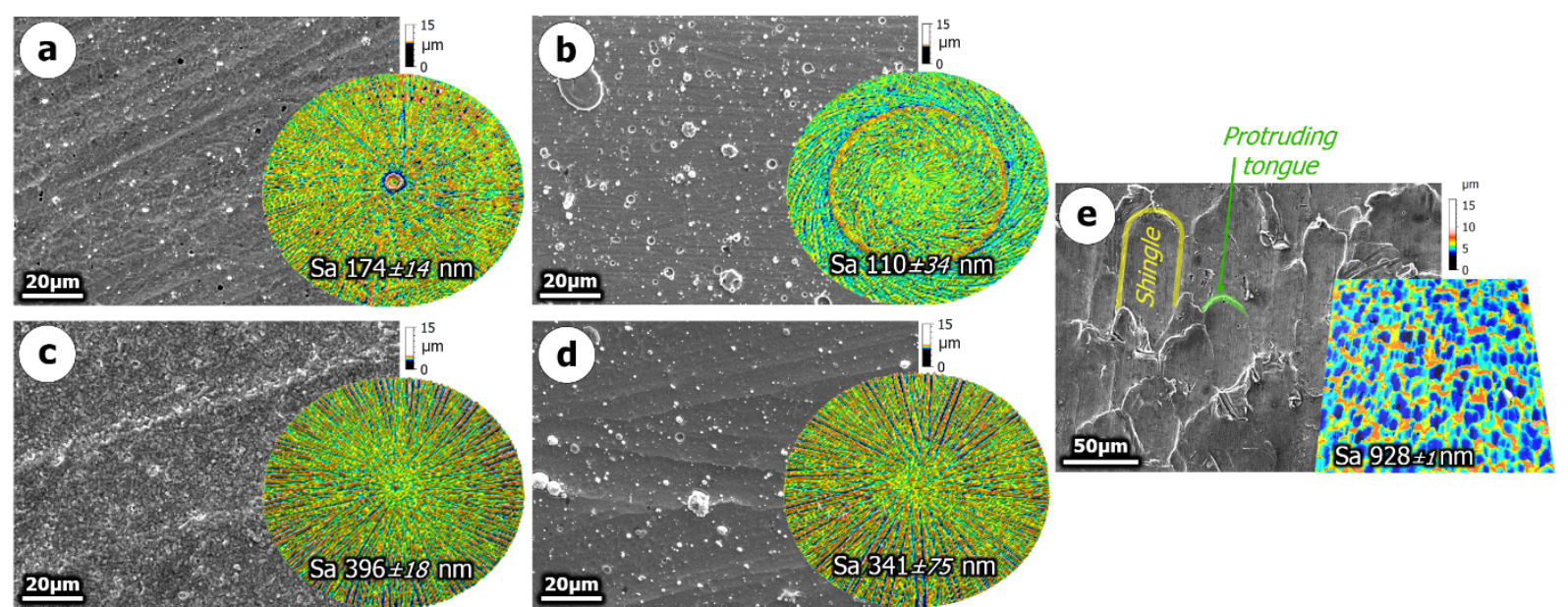

Fig. 4 As-received SEM micrographs and topographies of the (a) CrAlN, (b) CrTiN, (c) DLC ta-C, (d) CrN PVD coated tool steel samples and (e) aluminium sample (topography of area: pins $\varnothing 4 \mathrm{~mm}$, aluminium $1 \mathrm{~mm}^{2}$ )

EDX on the CrTiN (Fig. 4(b)) and CrN (Fig. 4(d)) coated samples, respectively. Craters are also observed and these are either created from the removal of droplets or induced by the PVD deposition process. The DLC ta-C coatings (Fig. 4(c)) show a more granular surface morphology. The initial roughness of the substrate is still visible even after the coatings were deposited (especially visible for the CrAlN, DLC ta-C, and $\mathrm{CrN}$ micrographs in Fig. 4). The surface features on the aluminium samples are oxidised shingles (composed of lower gorges and protruding tongueshighlighted in Fig. 4(e)), gorges and rolling grooves, which are typical from the hot sheet rolling process [3].

All of the pins exhibited a radially oriented roughness lay as shown in Fig. 4, which enabled to position them in any direction with respect to sliding direction. It should be noted that the surface topography of the CrTiN coated pins (Fig. 4(b)) was different compared to the other specimens, as they displayed a central flatter surface and radially curved roughness marks around the circumference. The aluminium countersurface topography is show in Fig. 4(e).

In order to assess the differences in surface morphology induced by the post-polishing process, 3D topography measurements of the mirrorpolished surfaces were also carried out. The obtained morphologies are shown in Fig. 5. The polishing led to a relatively smooth surface finish, compared to the as-received topographies. However, some defects were still be observed, more pronounced on the post-polished CrTiN (Fig. 5(a)) than the post-polished CrN coating (Fig. 5(b)). These defects are either local defects initially present on the as-received specimens (e.g. droplets and craters), or remains of the initial topography lay, which could not fully be removed by the manual-polishing (radial grooves visible in Fig. 5(b)).

\subsection{Overview of the wear tracks}

Figure 6 shows typical worn surfaces of both the PVD coated tool steel pins and aluminium samples after different tests. The results chosen for this example were all from tests with CrN PVD coatings under dry condition (Fig. 6(a)), in as-received lubricated condition (Fig. 6(b)) and post-polished lubricated condition (Fig. 6(c)).
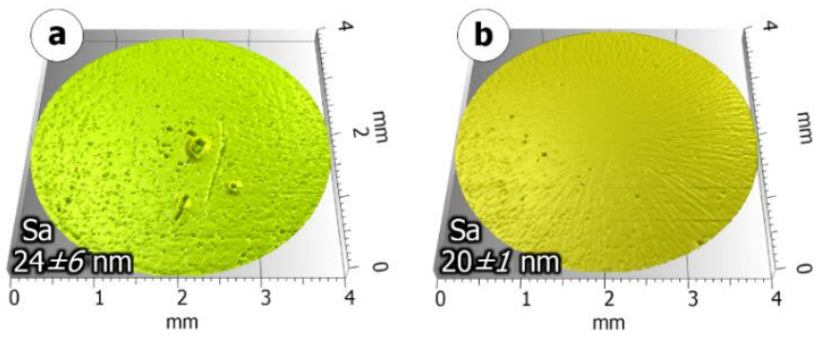

Fig. 5 Post-polished topographies of (a) CrTiN and (b) $\mathrm{CrN}$ PVD coated tool steel samples. 

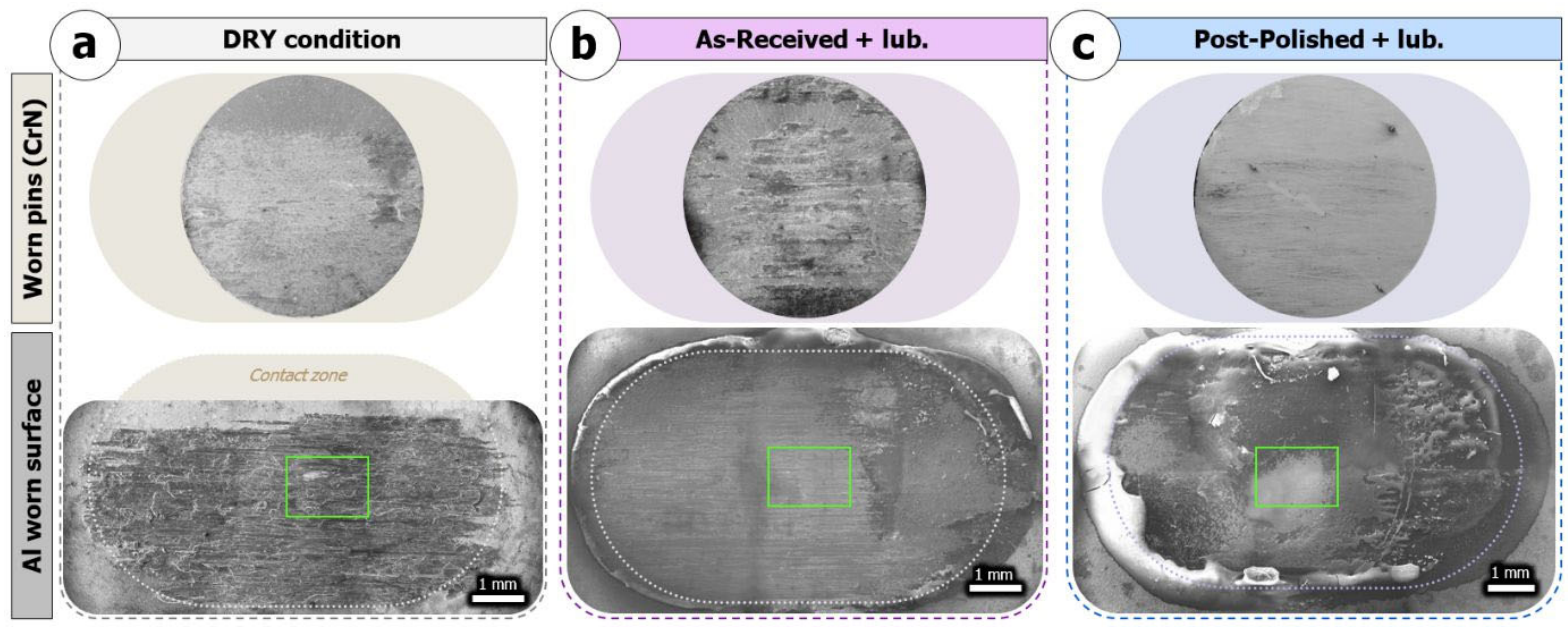

Fig. 6 Overview of the wear tracks on both $\mathrm{CrN}$ coated pin and aluminium specimens highlighting the main areas of interest for the test in (a) dry, (b) lubricated as-received, and (c) lubricated post-polished pin conditions.

The pins exhibit different severity of wear depending on the contact conditions, which will be further described in the following sections. The SEM micrographs of the aluminium samples in following sections are taken around the mid-regions of the wear scars (as highlighted in Fig. 6). The reasons for this choice are firstly due to diameter of the pin compared to the stroke length, which led to a full travel of its surface only over the centre part of the wear scar. Secondly, the sliding velocity was maximum and constant around the centre part of the wear scar due to the reciprocating movement. Thirdly, the most significant differences in terms of wear are observed in this region. Under lubricated conditions, the wear tracks on the aluminium samples were similar to the ones shown in Figs. 6(b) and 6(c). The lubricant was found to be spread over the aluminium sample and thicker residues accumulated around the wear track edges.

\subsection{Tests results-As-received topographies}

surface

\subsubsection{Dry tests}

Dry sliding tests were performed using the DLC ta-C and CrN PVD coated specimens as literature shows that using only protective coatings without lubrication, is not sufficient to improve friction or wear $[23,28,29]$. Those tests were thus carried out as reference test, in order to observe if the lubricant chose in the present study was leading to any improvement in the tribological contact. Figure 7 shows that the dry tests using these two coatings led to very high friction levels from the very beginning of each test, reaching the cut-off friction value of the tribometer (COF equal to or above 2.5).

Severe wear was observed when no lubrication was used, which is in accordance with results available in the open literature [23, 28, 29]. The SEM micrographs obtained from the dry tests with DLC ta-C and CrN coated tool steels are shown in Figs. $8(\mathrm{~b})$ and $8(\mathrm{c})$, respectively. Severe material transfer developed on both PVD coated specimens in the form of thick lumps of aluminium. The preferential location for the formation and build-up of these lumps were the initial roughness grooves and local defects on the pin surfaces, which is in agreement with previous studies [30]. The high friction is thus due to the occurrence of severe adhesive wear, in dry sliding.

The difference in the worn surfaces seems to come from a stronger bonding of the transferred aluminium on to the PVD coatings compared to the uncoated tool steel. In the case of the DLC ta-C coating, evidence of back transfer in the form of aluminium particles exhibiting a topographical orientation differing from the sliding direction can be seen on the pin surface (as highlighted in 


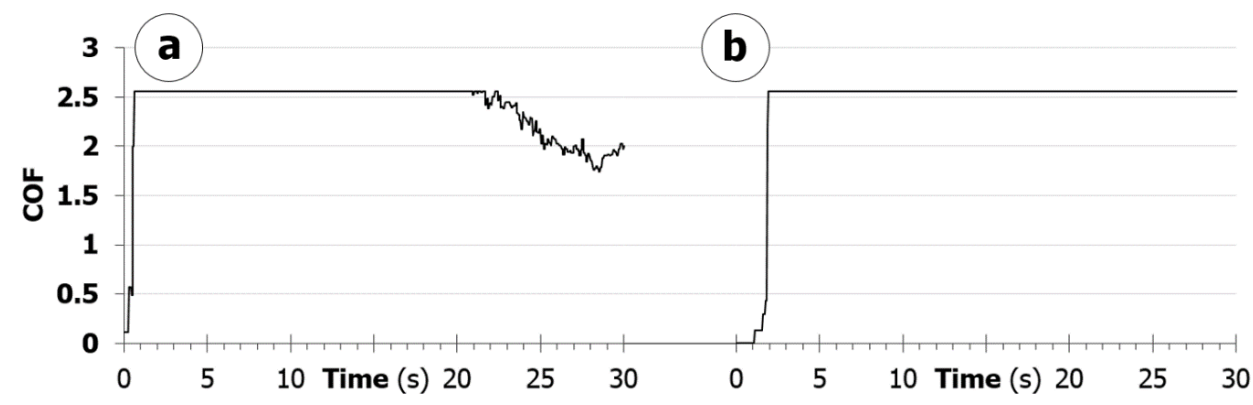

Fig. 7 Evolution of the COF during the dry tribotests for as-received (a) DLC ta-C and (b) CrN coated tool steel (load $10 \mathrm{~N}$, stroke length $4 \mathrm{~mm}$, frequency $12.5 \mathrm{~Hz}$, temperature $300^{\circ} \mathrm{C}$, dry).
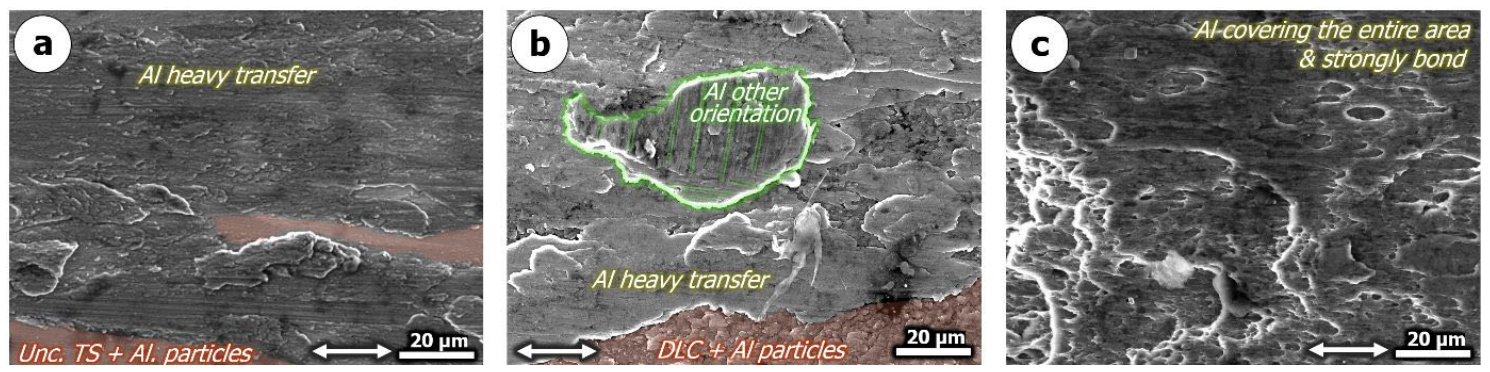

Fig. 8 Micrographs after the dry tests of (a) uncoated, (b) DLC ta-C coated, and (c) CrN coated tool steel samples, with highlighted dominant wear features.

Fig. 8(b)). In the case of the CrN coated samples, the adhered material covered a larger part of the contact. The appearance of this layer suggests that it has been exposed to shearing (Fig. 8(c)). This can result from strong bonding to both the $\mathrm{CrN}$ coating and the aluminium. The layered morphology of the material transfer suggests the progressive development of thick lumps of aluminium on the surface, one layer on top of the other. This appearance can be explained from the amount of aluminium transferred to the pin, as the contact progressively changed from a $\mathrm{CrN}$ coating-onaluminium to an aluminium-on-aluminium contact. The high surface coverage of the aluminium transfer can be attributed to the higher roughness of the $\mathrm{CrN}$ coated samples (Fig. 3). The local roughness of this coating, shown in Fig. 4, promoted mechanically initiated transfer of aluminium. Once initiated, this material transfer rapidly grows unless healing (e.g., oxidation of the transferred and highly reactive fresh aluminium) occurs [22]. The rougher surface and sharp protrusions present on the CrN PVD coating are thus likely to have prevented this recovery process by ploughing the oxidised aluminium surface, continuously exposing reactive aluminium.

\subsubsection{Lubricated tests}

For all PVD coatings, a significant decrease in friction was observed when the lubricant was applied in the contact zone, as compared to that in the dry tests. The use of lubrication significantly alleviated material transfer to the pin specimens and damages observed on the aluminium specimens, as shown by comparing the worn surfaces obtained from the dry (Fig. 6(a)) and as-received lubricated (Fig. 6(b)) tests. The adhesive wear was reduced in those latter tests through the development of tribolayers on the pin specimens (visible in Fig. 6(b)) which also lowered the wear taking place on the aluminium samples.

Carbon and silicon rich tribolayers, coming from the lubricant, formed in the contact zone and prevented occurrence of instantaneous adhesion. The properties of these tribolayers differed depending on the coatings on the pin samples.

\section{(1) CrAlN and CrTiN}

The friction levels when using the CrAlN and CrTiN PVD coatings are shown in Fig. 9, and 
exhibit a short steady-state followed by an increasingly erratic behaviour towards the end of all tests. Even though, the roughness of these PVD coatings was lower than that of the DLC ta-C and CrN coatings (as shown in Fig. 3), the observed steady-state friction levels and duration were lower.

The temporal friction curves shown in Figs. 9(a) and 9(b) clearly display the unstable friction behaviour obtained during the tests using the CrAlN and CrTiN coated samples. The friction remains at a relatively stable and low level of around 0.3 for less than half of the test duration, but suddenly changes to an unstable behaviour and reaches high friction levels towards the end of the test. The final friction values reached the tribometer cut-off value of 2.5. This indicates that the lubricant is effective for a certain duration, then, severe adhesion occurs as soon as the lubricant fails.

In terms of wear mechanisms, the CrAlN and CrTiN coated pin samples behaved in a similar manner compared to the uncoated tool steel. Figs. 10(a) and 10(c) show the type of tribolayer formed in the contact zone. The detailed study of these layers revealed a granular structure indicating

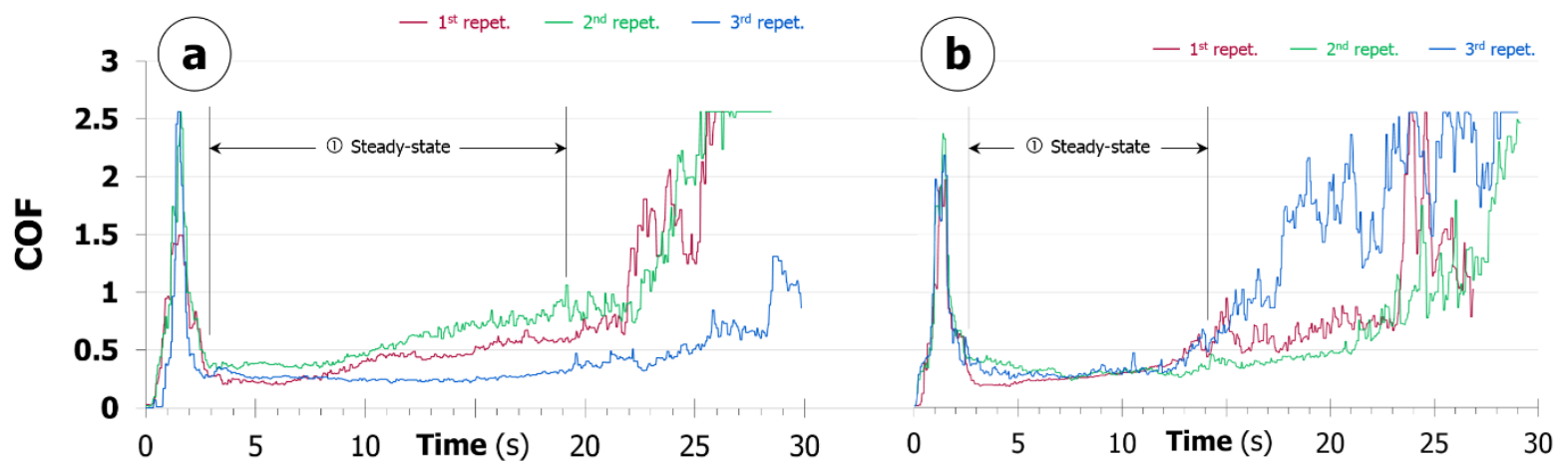

Fig. 9 Evolution of the COF during the polymer lubricated tribotests for the as-received (a) CrAlN and (b) CrTiN coated tool steel (load $10 \mathrm{~N}$, stroke length $4 \mathrm{~mm}$, frequency $12.5 \mathrm{~Hz}$, temperature $300^{\circ} \mathrm{C}$, lub.).
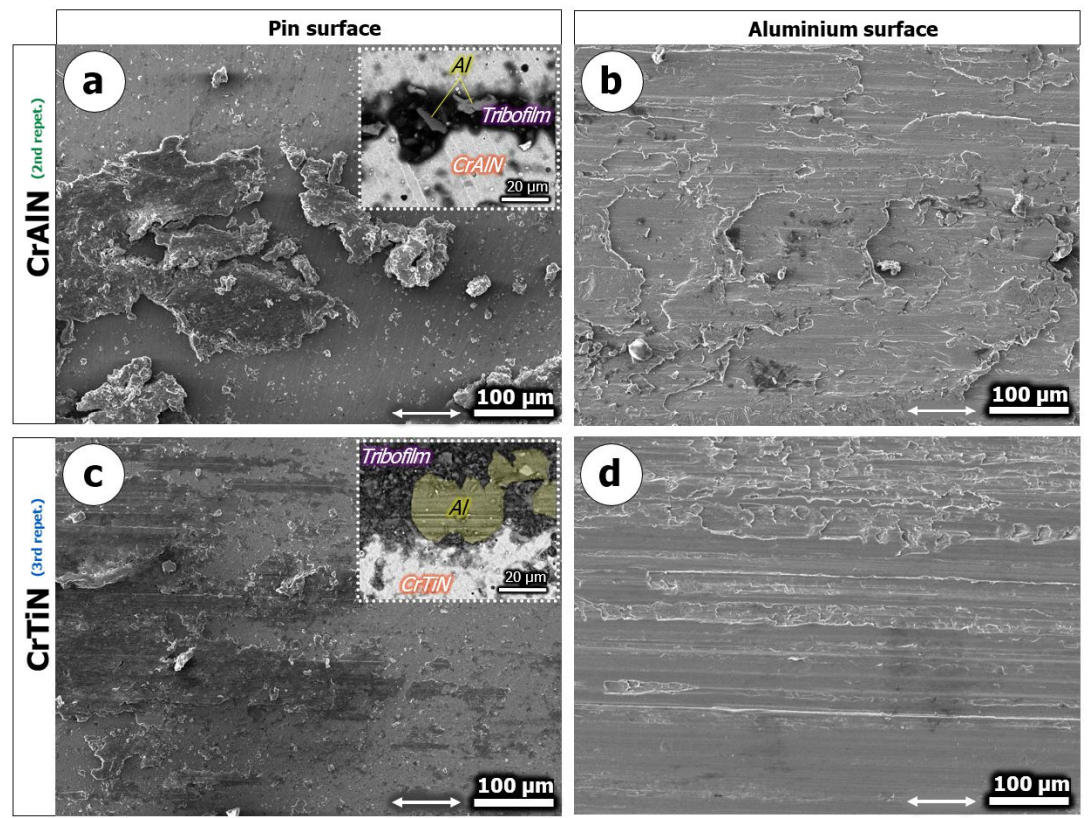

Fig. 10 SEM micrographs at $200 \times$ of (a) as-received CrAlN coated tool steel pin (BSE detail at $1 \mathrm{k} \times$ ) and (b) its aluminium counterface, (c) the as-received CrTiN coated tool steel pin (BSE detail at $1 \mathrm{k} \times$ ) and (d) its aluminium counterface sample ( $\leftrightarrow$ indicates the sliding direction). 
poor cohesion even in the most compacted zones. The EDX analysis confirmed that the composition of the tribolayers is mainly carbon and silicon, originating from the lubricant, and aluminium was found as particles embedded in the tribolayer (as seen in the BSE details in Figs. 10(a) and 10(c)). The layers nevertheless underwent a progressive breakdown, through fracture and comminution of the compacted layers into smaller sharp debris. Furthermore, as seen in Figs. 10(a) and 10(c), the surface coverage of those tribolayers was low, leaving exposed areas of the PVD coatings where adhesion could initiate. In some of those areas, severe material transfer took place, which resulted in the damages observed on the aluminium counter-surface shown in Figs. 10(b) and 10(d) (e.g. smearing, flaking, and severe plastic deformation). The observations of the worn surfaces correlate with the friction behaviour shown in Fig. 9. The steady-state level (directly following the initial peak as highlighted in Fig. 9) occurs when the lubricant provides full protection (low initial CoF). After this, a transition occurs when the layers start to break down (transition $\mathrm{CoF}$ ), and the last stage of erratic and high friction (end CoF) correlates the severe adhesion taking place towards the end of the test.

\section{(2) DLC ta-C and CrN}

As shown in Fig. 11, the use of the DLC ta-C and CrN PVD coatings led to the lowest and most stable friction levels of all the as-received samples tested. The stability of the coefficient of friction is significantly improved compared to that of the other two PVD coatings (apart from the similar initial static-to-dynamic friction peaks). A constant and slight increase is still observed but the final levels are much lower (around 0.5) than in the case of the CrTiN or CrAlN coatings (around 1.8). This behaviour suggests that a more gradual change in the tribological contact takes place than when using the latter coatings.

When analysing the worn surfaces of the DLC ta-C and $\mathrm{CrN}$ coated samples, compact carbon and silicon-rich tribolayers on the surfaces have been observed (as shown in Figs. 12(a) and 12(c)).

For the DLC ta-C coated samples, the developed tribolayers are more compact and smoother than on the CrN coated samples (Fig. 12(a)). Grooves, parallel to the sliding direction, on the tribolayers also confirm that these were load bearing during the test. It is also noticeable (Fig. 12(b)) that the main wear mechanism taking place on the aluminium samples was mild abrasion, indicating that there are also some hard constituents in the tribolayer. The protective layer thus efficiently prevented occurrence of adhesion, and only small fragments of aluminium were sparsely found on the DLC ta-C coating that was not covered by a tribolayer.

Concerning the $\mathrm{CrN}$ coated samples, the protective tribolayer covered a significant part of the contacting surface of the pin. As can be seen in Fig. 12(c), this layer is compact, visibly thicker than that in the DLC ta-C case, and effectively protect the surface underneath. Similarly, to the DLC ta-C, no significant aluminium transfer is seen on the surface and mild abrasion is the main wear mechanism observed on the aluminium

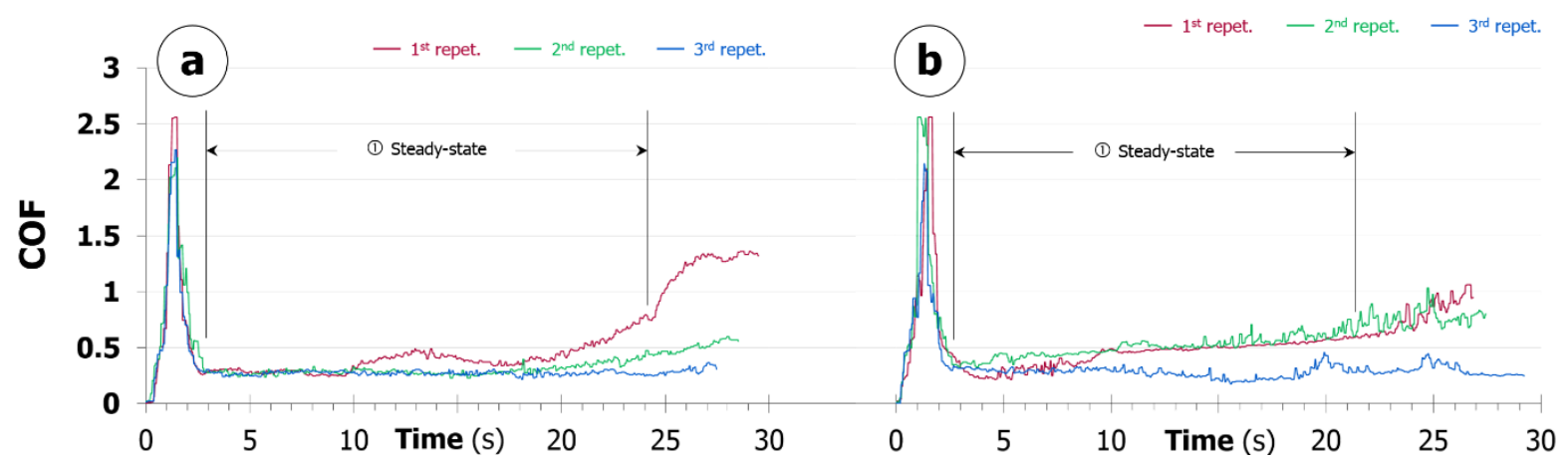

Fig. 11 Evolution of the COF during the polymer lubricated tribotests for as-received (a) DLC ta-C and (b) CrN coated tool steel (load $10 \mathrm{~N}$, stroke length $4 \mathrm{~mm}$, frequency $12.5 \mathrm{~Hz}$, temperature $300^{\circ} \mathrm{C}$, lub.). 
counterpart (as shown in Fig. 12(d)). Grooves parallel to the sliding direction are visible on this tribolayer, suggesting that the contact took place on this load-bearing layer.

\subsubsection{Nanoindentation of tribolayers}

Nanoindentation was carried out on the worn as-received $\mathrm{CrN}$ coated pin surface, with the aim of understanding the elastic/plastic behaviour of the PVD coated surface (Fig. 13(c)) and the tribolayer (Figs. 13(a) and 13(b)). The locations of the indentations are highlighted in Fig. 13(d). It is important to note that the nanoindentation curves are largely affected by the roughness and surface defects of the coating as well as the heterogeneity, roughness, brittleness and/or ductility of the
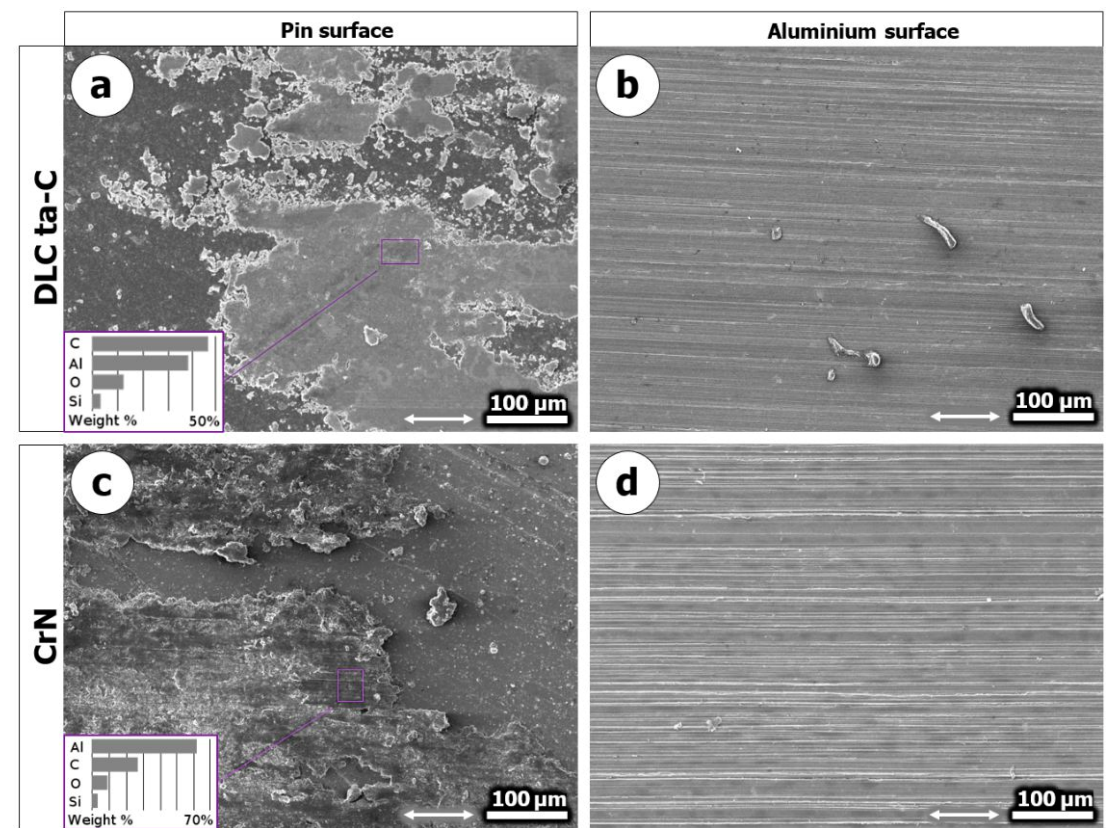

Fig. 12 SEM micrographs at $200 \times$ of (a) as-received DLC ta-C coated tool steel pin, (b) its aluminium counterface sample, (c) as-received $\mathrm{CrN}$ coated tool steel pin, and (d) aluminium counterface sample ( $\leftrightarrow$ indicates the sliding direction).
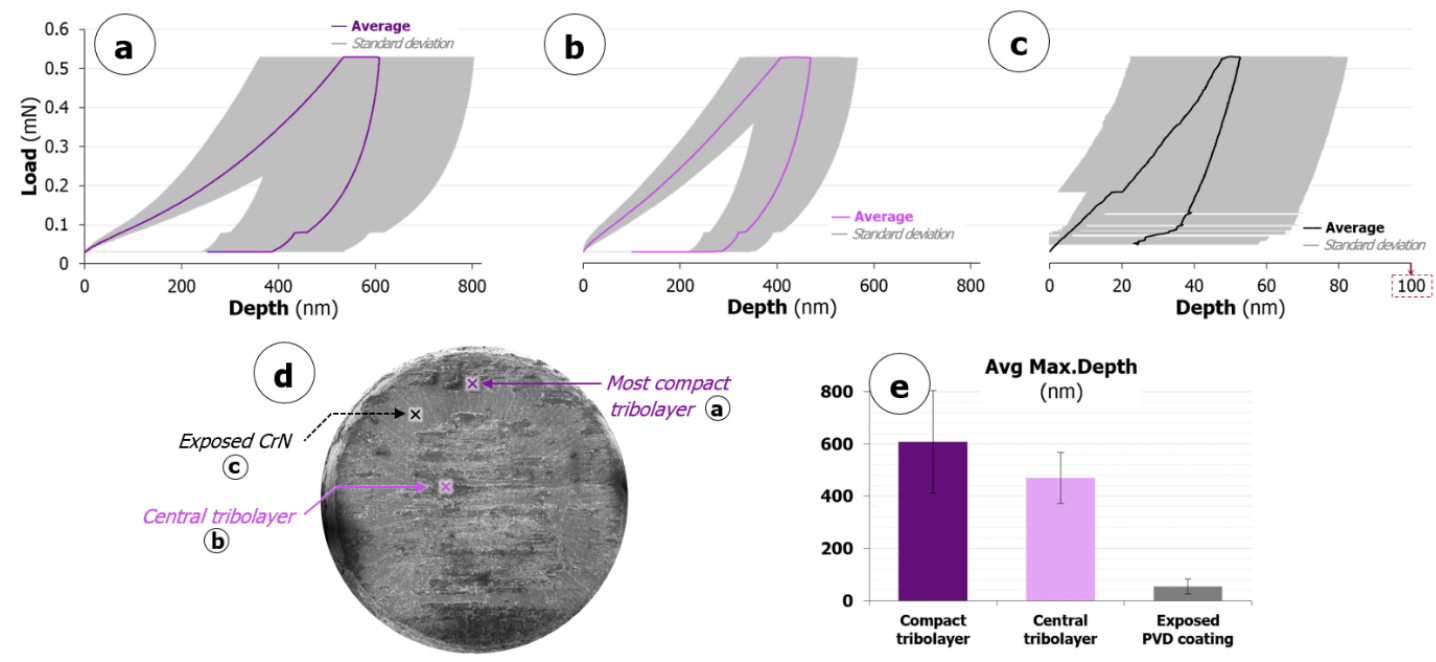

Fig. 13 Load vs. penetration depth from the nanoindentation at $0.5 \mathrm{mN}$ of as-received CrN coated pin samples after the lubricated tests. (a) Compact tribolayer at the top of the contact zone, (b) tribolayer at the central location, (c) exposed PVD coating (please note the difference in the depth scale for that graph), (d) highlights of the different indented locations on the pin sample, and (e) average maximum depth of the different zones (load $0.5 \mathrm{mN}$, load rate $0.0167 \mathrm{mN} / \mathrm{s}$, dwell time at maximum load $30 \mathrm{~s}$, thermal drift correction $30 \mathrm{~s}$ ). 
tribolayers. Thus, relatively large scatter can be seen in the measurements. Despite this, some trends can be distinguished from the measurements. In view of the significant scatter, the actual hardness values are not considered for this analysis, but the focus is mainly on the behaviour during loading/unloading and on the penetration depths.

The maximum penetration during loading did not exceed $100 \mathrm{~nm}$ for the exposed PVD coating (as shown in Figs. 13(c) and 13(e)). On the other hand, the maximum penetration into the tribolayers ranged between 400 and $700 \mathrm{~nm}$ (as summarised in Fig. 13(e)). This means that the tribolayers are relatively thick, soft, and ductile. Indeed, as the same load was used for all the different regions, a higher maximum penetration depth can be linked to a lower hardness and higher ductility of the indented layer. Moreover, the penetration being four to seven times higher than in the case of the exposed PVD coating is correlated to the relative thickness of the layer before the indenter would reach the coating underneath. The ductility of the tribolayers will increase at higher temperature, making these layers easily sheared between the aluminium and PVD coating. This can explain the low and stable friction.

These findings globally are in agreement with the low and stable friction behaviour observed in Fig. 11. The tribolayers, once formed in the contact zone, effectively prevent adhesion and withstand the contact stresses throughout the entire test duration. The slight increase in friction at the end of the test may be attributed to the initiation of tribolayer failure, as debris can be seen in
Figs. 12(a) and 12(b). Nevertheless, the total surface coverage and cohesion of those tribolayers is higher than the ones developing on the CrAlN and CrTiN. These properties explain the significant improvement in the tribological behaviour obtained when using the DLC ta-C and CrN coated samples.

\subsection{Tests results-Post-polished surface topographies}

In order to characterise the impact of PVD coating roughness on the tribological response of the coated tool steel-aluminium tribopairs, selected coatings were manually post-polished. As observed previously, two different behaviours were clearly identified in the as-received state tests. The CrAlN and CrTiN coatings on one hand led to unstable friction and wear behaviour, whereas the DLC ta-C and CrN coatings led to significantly low and stable friction and wear. It was thus chosen to study the effect of post-polishing the CrTiN (representative of the least beneficial behaviour in its as-received state) and $\mathrm{CrN}$ (representative of the best behaviour) PVD coatings. In addition, knowing that dry sliding results in severe adhesion and aluminium transfer even in the polished state [30], the post-polished samples were only evaluated under lubricated conditions.

The temporal evolution of friction in case of CrTiN is shown in Fig. 14(a). Even though a sharp transition occurred between the low and final $\mathrm{COF}$, a significant improvement both in terms of friction levels and stability (COF of $0.07 \pm 0.01$ ), is observed at the beginning of the test. The duration of this

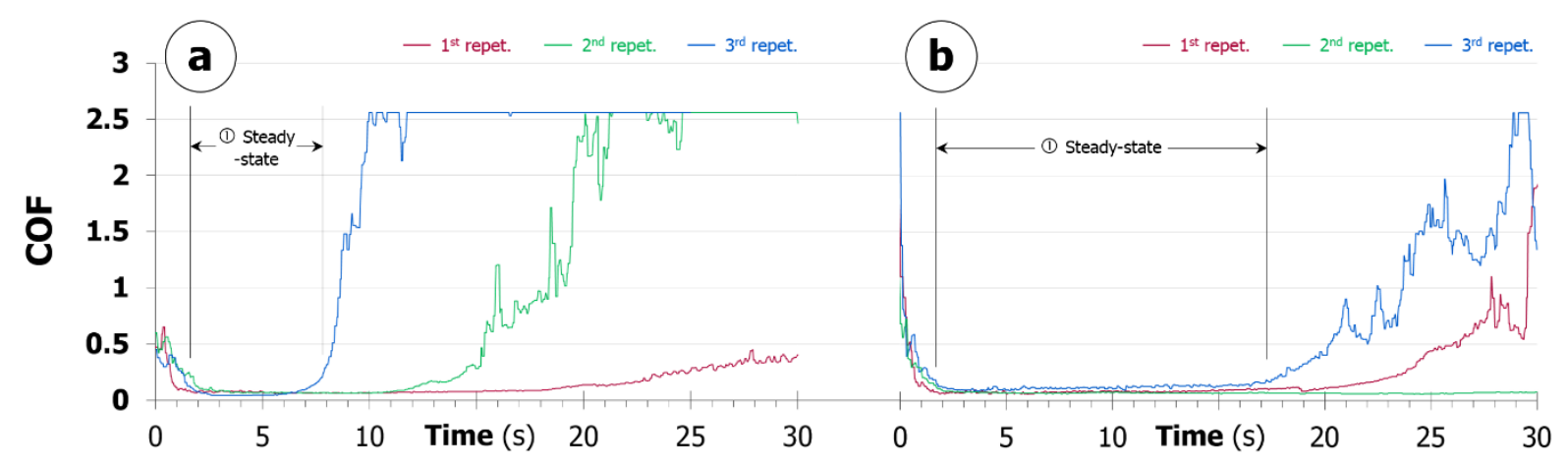

Fig. 14 Evolution of the COF during the polymer lubricated tribotests for (a) post-polished CrTiN coated tool steel and (b) post-polished $\mathrm{CrN}$ coated tool steel (Load $10 \mathrm{~N}$, stroke length $4 \mathrm{~mm}$, frequency $12.5 \mathrm{~Hz}$, temperature $300{ }^{\circ} \mathrm{C}$, lub.). 
improvement is between 5 and 18 seconds, leading to a high standard deviation from one test to another. This suggests that the formation of a stable tribolayer varies between different tests. This high deviation can be attributed to the topography of the samples (as shown in Fig. 5(a)) exhibiting many randomly distributed defects. It is observed that the CrTiN coating in the as-received state has a tendency towards unstable behaviour once the lubricant layer fails, and direct contact between the coating and aluminium occurs. In this case, the smoother surface results in low COF but the surface defects lead to the lubricant failure, inducing the observed unstable behaviour.

The best improvement in terms of friction out of all test configurations was obtained with the post-polished CrN coated samples (shown in Fig. 14(b)). A significant improvement in frictional stability is observed over the longest period of all test configurations with an average COF of $0.08 \pm 0.01$ for more than 15 seconds. The low and stable friction levels changed with a sharp transition to a higher level towards the end for two out of three tests.

An important consideration is that, even in the best cases where friction levels were low and stable, material transfer could not be completely prevented (as seen in Fig. 15). Aluminium transfer still initiated at local defects in the form of roughness grooves and/or PVD coating defects that the polishing process could not remove. Nevertheless, compared to the cases when material transfer initiates due to the tribolayer failure, the material transfer observed in the post-polished cases is significantly thinner and sparse. The surface coverage of this latter type of transfer is particularly low and the type of patches shown in Fig. 15 are only sporadically found on the worn surfaces. This explains why the friction levels remained low and stable even though aluminium transferred to the counter material.

The SEM micrographs of the worn post polished CrTiN and CrN coated samples and the corresponding aluminium counter surface are shown in Figs. 16(a)-16(d). Noticeably, no tribolayer could be found on the PVD coated pin samples, as even the EDX analyses of these surfaces only revealed traces of carbon and silicon. These samples exhibit no significant wear or material transfer from the aluminium counterpart. Interestingly, the aluminium counter surfaces show three different areas. One with the lubricant layer, one flattened areas and reservoirs of the remaining lubricant layer, and exposed aluminium as shown in Fig. 16(b).

Considering the post-polished $\mathrm{CrN}$ coated samples, a similar wear behaviour to the tests with post-polished CrTiN samples has been observed. No tribolayer developed on the pin surface, as can be seen in the Fig. 16(c). No significant wear took place on those samples, nor did significant material transfer occur from the aluminium samples. The aluminium counter surface exhibited the same type of feature (Fig. 16(d)). The EDX mapping of these features revealed the same kind of mixed structure of the flattened areas (e.g. with voids and embedded Si particles) and reservoirs of the remaining lubricant layer (as shown in
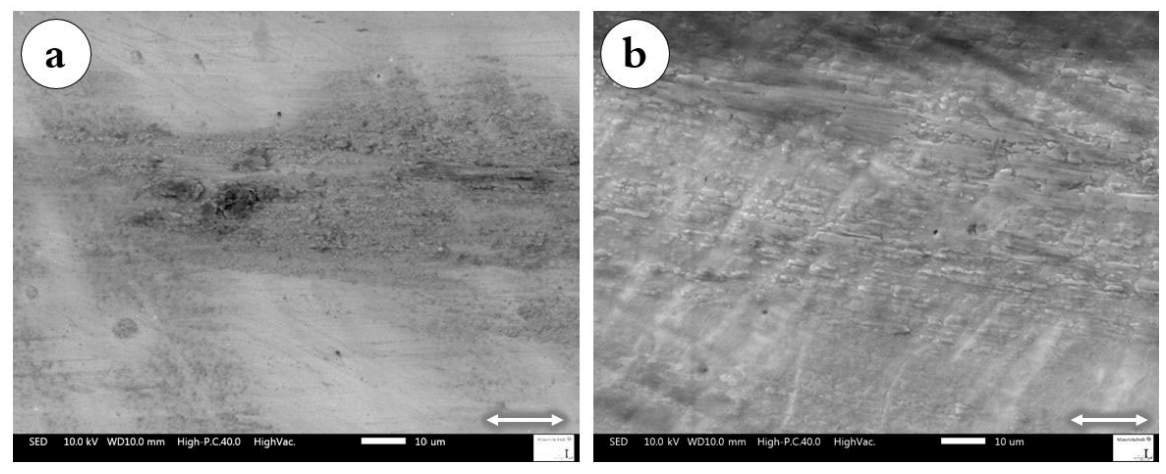

Fig. 15 SEM micrographs at $1 \mathrm{k} \times$ and $10 \mathrm{kV}$ of the post-polished (a) CrTiN and (b) CrN coated tool steel tests showing the aluminium transfer patches ( $\leftrightarrow$ indicates the sliding direction). 
Figs. 16(b) and 16(d)). Initial shingle features are still visible under this lubricant layer, acting as reservoirs, before the protruding tongues would enter the contact and be mechanically mixed into the flattened areas.

Further analysis of the features shown in Figs. 16(b) and 16(d), revealed that the flattened mechanically mixed areas are formed by aluminium with embedded silicon particles (Fig. 17). Surrounding these layers, carbon and silicon-rich layers are observed (highlighted in Figs. 16(b) and 16(d)), and these can be attributed to the remaining lubricant itself. The initial topography of the aluminium samples enabled the development of both types of layers; in the as-delivered condition, the shingles (shown in Fig. 4) initially present a lower bottom part and protruding tongues. The valleys on the surface of the aluminium specimen act as reservoirs for the lubricant as shown in Fig. 16(b) and d as well as Fig. 17. On the other hand, the protruding asperities of the aluminium surface enter the contact and are mixed with the lubricant (as shown by the EDX maps in Fig. 17), spread, and
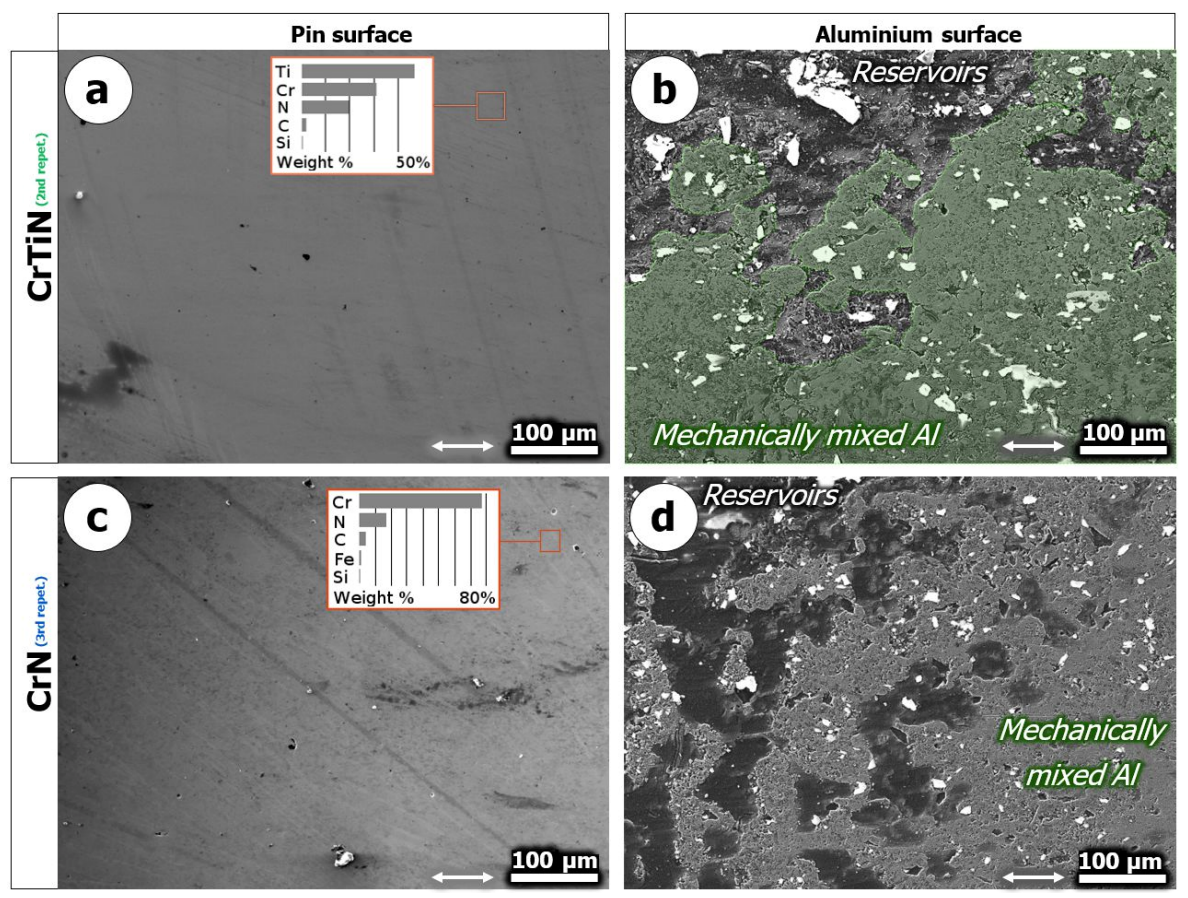

Fig. 16 SEM micrographs at $200 \times$ of (a) post-polished CrTiN coated tool steel pin and (b) its aluminium counterface sample, (c) post-polished $\mathrm{CrN}$ coated tool steel pin, and (d) its aluminium counterface sample (↔ indicates the sliding direction).
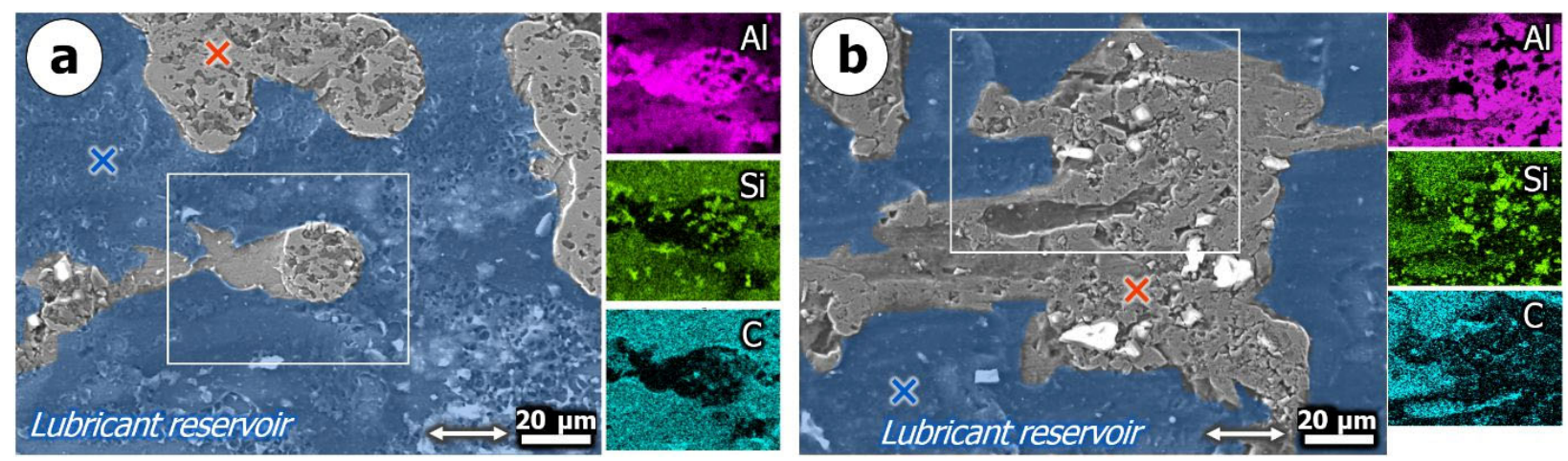

Fig. 17 SEM micrograph at $750 \times$ and EDX maps focussing on the worn features of the aluminium sample used against (a) post-polished $\mathrm{CrTiN}$ coated tool steel and (b) post-polished $\mathrm{CrN}$ coated tool steel $(\leftrightarrow$ indicates the sliding direction; $\times$ indicates the nanoindentation areas: orange $\times$ load-bearing; blue $\times$ lubricant reservoir). 
flattened.

\subsubsection{Nanoindentation of tribolayers}

The worn aluminium surfaces after sliding against the post-polished $\mathrm{CrTiN}$ and $\mathrm{CrN}$ coatings were analysed using nanoindentation. The results show a similar behaviour when considering the tests carried out against the post-polished $\mathrm{CrN}$ pins. The following Fig. 18 thus exemplifies the results obtained from sliding against the post-polished CrTiN coating only. Indentation was carried out at various locations highlighted in Figs. 17(a) and 18(d). The location included the reference unworn aluminium (e.g. out of the wear track on the sample), the mechanically mixed areas and the lubricant reservoirs. The respective obtained load vs. depth graphs are plotted in Figs. 18(a)-18(c).

The mechanically mixed areas show an intermediate behaviour, as some indentation curves are found to be similar to the lubricant reservoir results (Fig. 18(b)) and others similar to the unworn aluminium (Fig. 18(c)), which correlate with their mechanically mixed structure. These features are visibly heterogeneous, comprising embedded silicon particles as well as apparent craters and voids, as shown in Fig. 17.
The protective layers that developed on the aluminium are different compared to those developed on the previous as-received PVD coated pins. The latter are soft and thicker, as large penetrations (up to $700 \mathrm{~nm}$ ) are measured at the maximum load and after the unloading, a remaining penetration depth of $300-400 \mathrm{~nm}$ is observed (shown in Fig. 13). In the case of the aluminium specimens shown in Fig. 18, the maximum penetration is approximately $150 \mathrm{~nm}$ for both the areas with only remaining lubricant layers (reservoirs) and the mechanically mixed areas. The measurements carried out on the remaining lubricant layer show that it is very thin, as the maximum penetration depth is in the same range as that of the unworn aluminium. No large influence of viscoelastic/plastic behaviour is detected, as seen by the small increase in penetration depth at the maximum load (Fig. 18(b)). The mechanical properties of the remaining lubricant layer are quite different from the unworn aluminium, as the plastic deformation after unloading is significantly lower. This implies that the layer formed from those lubricant remains is hard and provides high elastic recovery, which can explain the protective nature of this layer and its
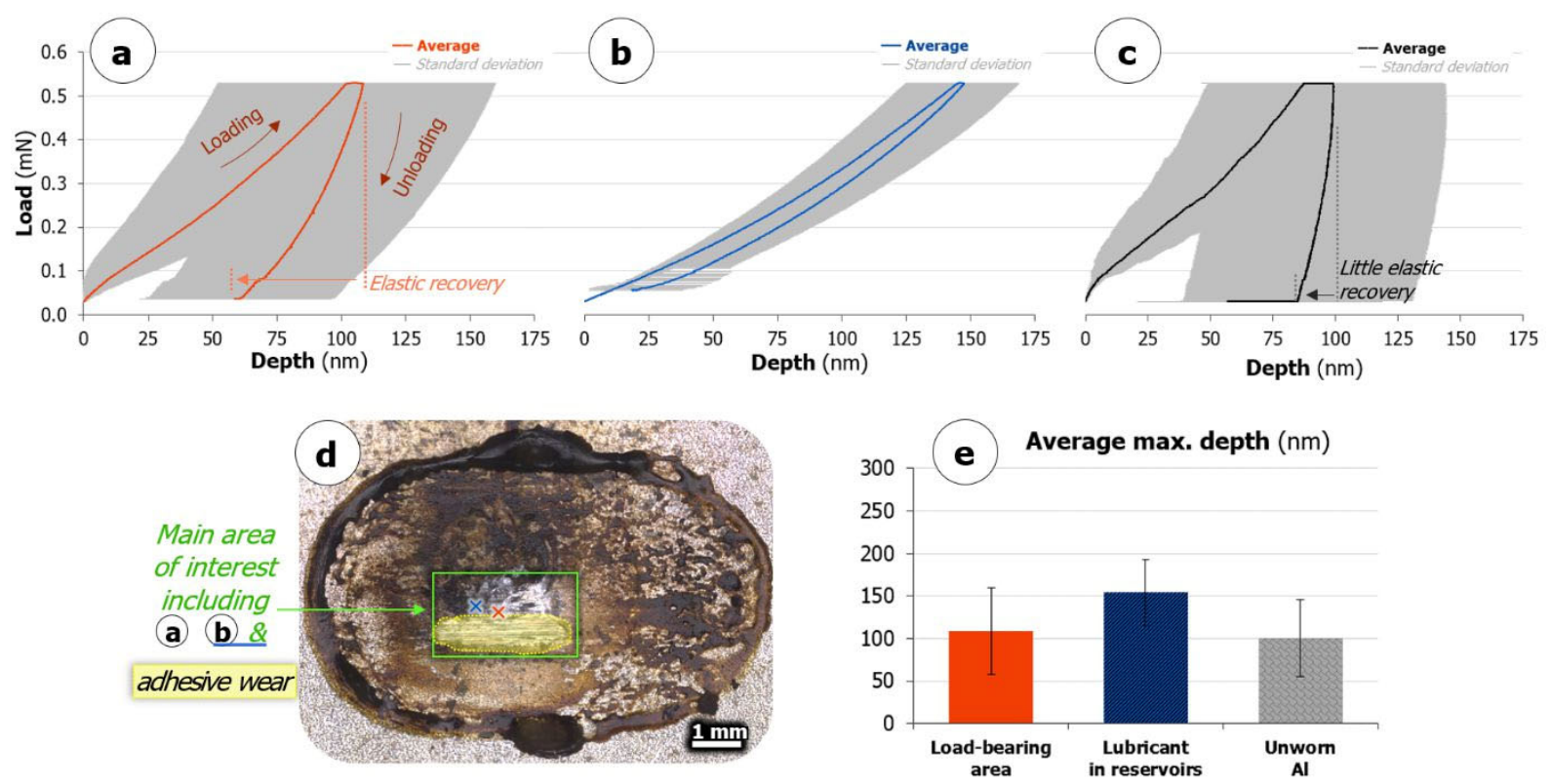

Fig. 18 Load vs. penetration depth from the nanoindentation of the aluminium samples tested against post-polished CrTiN pin samples under lubrication. (a) Load-bearing areas, (b) lubricant reservoirs, (c) unworn aluminium, away from the wear track, (d) highlights of the different indented locations on the aluminium sample, and (e) average maximum depth of the different zones (load $0.5 \mathrm{mN}$, load rate $0.0167 \mathrm{mN} / \mathrm{s}$, dwell time at maximum load $30 \mathrm{~s}$, thermal drift correction $30 \mathrm{~s}$ ). 
ability to prevent direct contact between the PVD coated surface and aluminium. The mechanically mixed layers (e.g. load bearing areas) show an intermediate behaviour (seen in Fig. 18(a)) between the remaining lubricant layer in the reservoirs (Fig. 18(b)) and the unworn aluminium (Fig. 18(c)). This suggests that once developed and flattened, the mechanically mixed zones offer sufficient mechanical support to maintain a conformal contact.

The nanoindentation results thus suggest that the friction behaviour for the post-polished tests is governed by the hard and protective nature of the lubricant layer on the aluminium surface as well as the smooth surface topography of the mechanically mixed layer. These results also show a clear difference in the tribolayers formed on the as-received pins compared to the post-polished case (e.g. on the aluminium).

Figure 19 shows a proposed schematic in four stages for the development of the particular features observed on the aluminium surface (seen in Figs. 16(b) and d as well as Fig. 17) during the tests using post-polished PVD coated specimens.
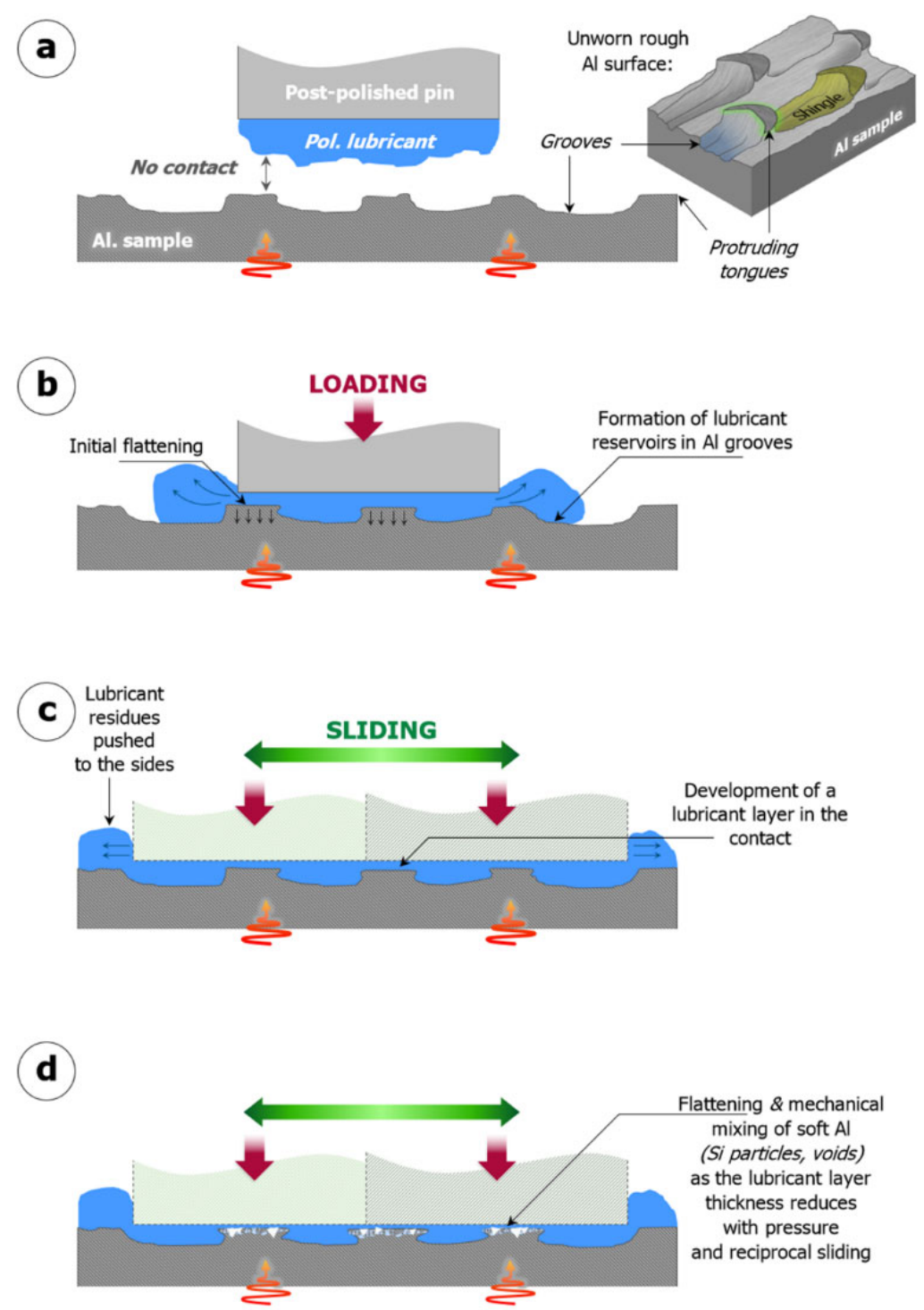

Fig. 19 Schematic progression of the contact at the asperity level between the post-polished coated pin and the aluminium sample showing four stages. (a) Initial surfaces before contact, (b) loading, (c) sliding with the development of a lubricant layer, and (d) critical point where mechanical mixing occurs and the lubricant layer becomes critically thin. 
The initial surfaces (not to scale), before the contact occurs, are shown in Fig. 19(a). Due to the active heating, the aluminium sample is softer than the pin when the contact occurs (Fig. 19(b)), the protruding features are thus flattened during the loading. At the same time, the lubricant is spread over the contact zone and fills the grooves and cavities existing on the rough aluminium surface. When sliding takes place (Fig. 19(c)), the polished surface of the pin specimens prevents mechanical anchorage of the lubricant. The lubricant is thus first spread over the entire $4 \mathrm{~mm}$ sliding zone, leading to a full lubricant layer to develop between the pin and aluminium sample. Remnants are progressively spread out of the contact zone. Once the progressive spreading reaches a critical point, the lubricant layer is much thinner and remains mainly in the asperities of the aluminium sample (Fig. 19(c)). The soft flattened aluminium asperities thus undergo mechanical mixing due to the tribological loads, resulting in the specific features shown in Figs. 18(b) and 18(d). After that stage, material transfer can initiate if sliding continues, as the remaining lubricant layer can fail and metallic aluminium be exposed.

A noticeable difference between the post-polished and the as-received PVD coatings is an abrupt change in the friction behaviour. The friction curves shown in Fig. 14 show a drastic increase from the initial stable friction levels to higher values than in the as-received cases (see Figs. 9(b) and 11(b)). This sharp change is even more pronounced in the CrTiN PVD coated case, due to initiation of transfer at the local defects (shown in Fig. 5). The lubricant failure thus appears to be critical in the post-polished tribological contacts.

The tribolayers developed on the as-received PVD coatings do not appear to undergo catastrophic failure and a relatively low friction can be maintained despite some direct contact between the exposed PVD coating and aluminium. In the case of the post-polished PVD coatings, protective layers do not develop on the PVD coated surface but on the aluminium counter surface instead. The failure of this layer results in direct contact between the PVD coating and bare aluminium, which leads to adhesion, material transfer and high friction. The lubricant layer covering the majority of the contact governs the low and stable friction behaviour. Once this layer starts to fail in the mid-region of the contact, the flattened mechanically mixed layers will develop which results in a gradual increase in friction. If sliding continues, the metallic aluminium will be exposed (e.g. in the tests with CrTiN) and immediate transfer to the PVD coating occurs with an abrupt increase in friction.

These changes in the steady-state regime under lubricated conditions are summarised in Fig. 20. In the as-received state, the use of PVD coatings mainly leads to an increase in the transition time of the friction level, as compared to the uncoated case. This improvement in the duration of the steady state can be linked to the resistance of the tribolayers formed on the pins. Indeed, the CrAlN and CrTiN coated samples exhibit granular and locally removed layers, whereas the $\mathrm{CrN}$ and DLC ta-C coated specimens show more compact and durable layers, leading to a longer steady-state. From the four as-received coatings, the $\mathrm{CrN}$ and DLC ta-C exhibit the longest time to transition, as observed from the temporal curves (shown in Fig. 11). Figure 20 also highlights that the tests using the $\mathrm{CrN}$ coated samples are less stable (in both the friction levels and transition time) than the DLC ta-C coated ones.

Using post-polished coatings clearly shows an improvement in the friction levels, as the

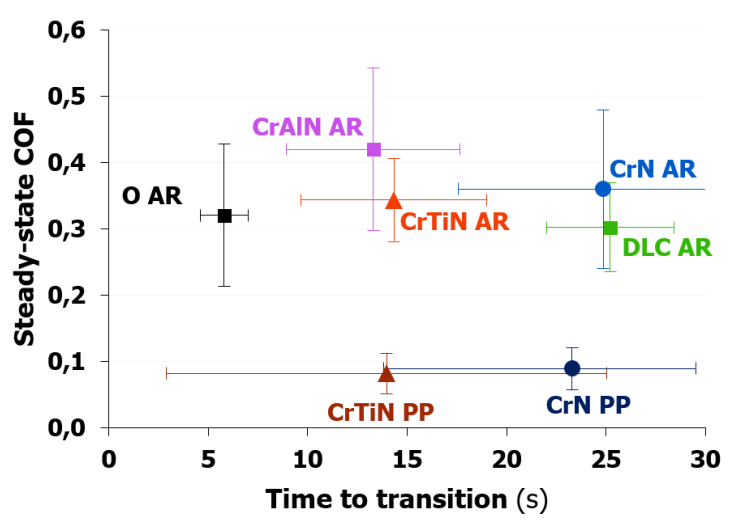

Fig. 20 Steady-state friction coefficient vs. time to transition in both as-received and post-polished cases. 
steady-state friction is four times less in both the CrTiN and $\mathrm{CrN}$ cases. Nevertheless, the sharp transition to extreme friction levels also becomes evident, as the average transition time is around the same in both as-received and post-polished cases, but exhibits a much (two to four times) higher deviation in the latter.

These results are in accordance with literature $[22,26,31]$, where tests performed using mirror-polished samples proved to be more stable and beneficial to the overall tribological behaviour. However, as observed in the present work and as pointed out in Refs. [22, 26, 31], the control of the surface topography is crucial. In lubricated cases, surface defects can initiate lubricant failure and direct contact between the aluminium and the counter surface occurs, leading to the abovementioned sharp and detrimental change of friction and wear behaviour.

\section{Conclusions}

In this study, the friction and wear behaviour of different PVD coatings sliding against aluminium were investigated at high temperature. The present work included the use of uncoated tool steel specimens as reference. Two roughness levels of the coated specimens were tested, in order to study its influence on the tribological behaviour. The use of a warm-forming polymer-based lubricant was also evaluated against dry sliding tests. The main conclusions from this study are as follow:

1) The coefficient of friction is significantly affected by the surface roughness of the PVD coatings and the lubrication. High and unstable friction is found in dry sliding conditions. Friction is reduced when using a lubricant with as-deposited PVD coatings. A further reduction and improved friction stability are accomplished when using polished PVD coatings with lubrication.

2) The dominant wear mechanism is severe adhesive wear in dry conditions. Reduced adhesive wear and mild abrasion on the aluminium surface are observed when using as-deposited PVD coatings with a lubricant. No significant material transfer can be detected on the polished PVD coated surfaces that were used with a lubricant.

3) The use of the polymer-based lubricant results in the formation of protective tribolayers on the as-received PVD coatings, which considerably reduces the aluminium transfer and friction. The DLC ta-C and CrN PVD coatings show the best results, due to improved coverage and durability of the tribolayers formed on these surfaces.

4) The polishing of the PVD coatings leads to a significant improvement in friction and less severe adhesive wear. However, the stability of this regime is greatly impacted by the roughness and local defects. The failure of the lubricant layer seems to be more dramatic when using polished coatings, as a sharp transition to extreme friction and wear has been observed in some cases.

5) Both chemical and topographical interactions need to be taken into account when selecting PVD coatings in conjunction with aluminium for high temperature lubricated sliding conditions.

\section{Acknowledgements}

The authors would like to acknowledge Swerea IVF (now RISE) for the financial and material support as well as their inputs for the realisation of this study.

Open Access This article is licensed under a Creative Commons Attribution 4.0 International License, which permits use, sharing, adaptation, distribution and reproduction in any medium or format, as long as you give appropriate credit to the original author(s) and the source, provide a link to the Creative Commons licence, and indicate if changes were made.

The images or other third party material in this article are included in the article's Creative Commons licence, unless indicated otherwise in a credit line to the material. If material is not included in the article's Creative Commons licence and your intended use is not permitted by 
statutory regulation or exceeds the permitted use, you will need to obtain permission directly from the copyright holder.

To view a copy of this licence, visit visit http://creativecommons.org/licenses/by/4.0/.

\section{References}

[1] Mendiguren J, Argandona E S D, Galdos L. Hot stamping of AA7075 aluminum sheets. In IOP Conference Series: Materials Science and Engineering, Linz, Austria, 2016: 012026.

[2] Fan X, He Z, YUAN S, Zheng K. Experimental investigation on hot forming-quenching integrated process of 6A02 aluminum alloy sheet. Mat Sci Eng A 573(20): 154-160 (2013)

[3] Gali O A. Micro-mechanisms of surface defects induced on aluminum alloys during plastic deformation at elevated temperatures. Ph.D Thesis. Windsor (UK): University of Windsor, 2017.

[4] Fridlyander I, Sister V, Grushko O, Berstenev V, Sheveleva L, Ivanova L. Aluminium alloys: promising materials in the automotive industry. Met Sci Heat Treat 44: 3-9 (2002)

[5] Das S, Morales A, Riahi A, Meng-burany X, Alpas A. Role of plastic deformation on elevated temperature tribological behavior of an Al-Mg alloy (AA5083): A friction mapping approach. Metall Mater Trans A 42: 2384-2401 (2011)

[6] Wan Y, Xue Q, Liu W. Tribological behavior of lubricating oil additives in lubricated aluminum-on-steel contact. Wear 196(1): 87-91 (1996)

[7] Riahi A, Edrisy A, Alpas A. Effect of magnesium content on the high temperature adhesion of Al-Mg alloys to steel surfaces. Surf Coat Technol 203(14): 2030-2035 (2009)

[8] Dwivedi D. Sliding temperature and wear behaviour of cast Al-Si-Mg alloys. Mat Sci Eng A 382(1): 328-334 (2004)

[9] Das S, Biswas S. Boundary lubricated tribology of an aluminium-silicon alloy sliding against steel. Tribol Lett 17(3): 623-628 (2004)

[10] Krajewski P, Morales A. Tribological issues during quick plastic Forming. J Mater Eng Perform 13(6): 700-709 (2004)

[11] Miyoshi K. Solid lubricants. In Encyclopedia of Tribology. Wang Q J, Chung Y W, Edn. Boston: Springer, 2013: 3159-3165.

[12] Matsumoto $\mathrm{K}$, Izawa $\mathrm{M}$, Nakanishi $\mathrm{T}$, Tsubouchi $\mathrm{K}$. Tribological properties of water glass lubricant for hot metalworking. Tribol Trans 52(4): 553-559 (2009)

[13] Cui S. Lubrication mechanism investigation of alkali polyphosphate glass in hot rolling. Ph.D Thesis. Wollongong (Australia): University of Wollongong, 2018.

[14] Erdemir A. Boron-based solid nanolubricants and lubrication additives. In Nanolubricants. Martin J M, Ohmae N, Edns. Chichester: Wiley \& Sons, Ltd., 2008: 203-223.

[15] Wei J, Erdemir A, Fenske G. Dry Lubricant Films for Aluminium Forming. Tribol Trans 43(3): 535-541 (2000)

[16] Tomala A, Rodriguez ripoll M, Badisch E. Tool- solid lubricant-workpiece interactions in high temperatures applications. Procedia Eng 68: 626-633 (2013)

[17] Erdemir A. Solid Lubricants and Self-Lubricating Films. In Modern Tribology Handbook. Bhushan B, Edn. Boca Raton: CRC Press, 2001: 787-825.

[18] Podgornik B, Kosec T, Kocijan A, Donik Č. Tribological behaviour and lubrication performance of hexagonal boron nitride (h-BN) as a replacement for graphite in aluminium forming. Tribol Int 81: 267-275 (2015)

[19] Hanna M, Krajewski P, Schroth J. Tribological testing of graphite and boron nitride lubricant formulations for high temperature aluminum sheet forming processes. In Proceedings of ASME/STLE International Joint Tribology Conference IJTC2007, San Diego, USA, 2017: 705-707.

[20] Wan S, Tieu K, Xia Y, Zhu H, Tran B, Cui S. An overview of inorganic polymer as potential lubricant additive for high temperature tribology. Tribol Int 102: 620-635 (2016)

[21] Pujante J, Vilaseca M, Casellas D, Riera M. The role of adhesive forces and mechanical interaction on material transfer in hot forming of aluminium. Tribol Lett 59(10): 8 (2015)

[22] Heinrichs J, Olsson M, Jacobson S. Mechanisms of material transfer studied in situ in the SEM: Explanations to the success of DLC coated tools in aluminium forming. Wear 292-293: 49-60 (2012)

[23] Ni W, Cheng Y, Weiner A M, Perry T A. Tribological behavior of diamond-like-carbon (DLC) coatings against aluminum alloys at elevated temperatures. Surf Coat Technol 201(6): 3229-3234 (2006)

[24] Pellizzari M, Zadra M, Molinari A. Tribological properties of surface engineered hot work tool steel for aluminium extrusion dies. Surf Eng 23(3): 165-168 (2007)

[25] Jerina J, Kalin M. Aluminium-alloy transfer to a $\mathrm{CrN}$ coating and a hot-work tool steel at room and elevated 
temperatures. Wear 340-341: 82-89 (2015)

[26] Pellizzari M. High temperature wear and friction behaviour of nitrided, PVD-duplex and CVD coated tool steel against 6082Al alloy. Wear 271: 2089-2099 (2011)

[27] Karbasian H, Tekkaya A E. A review on hot stamping. $J$ Mater Process Technol 210(15): 2103-2118 (2010)

[28] Azushima A, Uda K, Yanagida A. Friction behavior of aluminum-coated 22MnB5 in hot stamping under dry and lubricated conditions. J Mater Process Technol 212(6): 1014-1021 (2012)

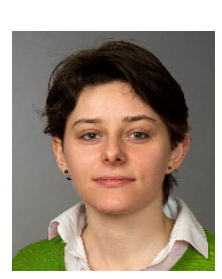

Justine DECROZANT-TRIQUENAUX. She received her M.Sc. in mechanical engineering in 2016 from Ecole Nationale d'Ingénieurs de Saint Etienne (ENISE), France. After then,
[29] Hosford W F, Caddell R M. Metal Forming-Mechanics and Metallurgy. 4th Edn. Cambridge (UK): Cambridge University Press, 2011.

[30] Heinrichs J, Olsson M, Jacobson S. New understanding of the initiation of material transfer and transfer layer build-up in metal forming-In situ studies in the SEM. Wear 292-293: 61-73 (2012)

[31] Salas O, Kearns K, Carrera S, Moore J. Tribological behavior of candidate coatings for Al die casting dies. Surf Coat Technol 172(2-3): 117-127 (2003)

she was a Ph.D. student at the Luleå University of Technology, Sweden. Her Ph.D. degree will be defended in mechanical engineering. Her research areas include high temperature tribology with a focus on sheet metal forming of aluminium. 